\title{
Cosmopolitismo y neobarroco en la narrativa de Adolfo Cárdenas Franco
}

\author{
Alberto David Rivera-Vaca \\ University of Central Arkansas
}

\begin{abstract}
This article analyzes the first stage of Adolfo Cárdenas Franco's narrative, beginning with the collection of short stories compiled in Fastos marginales (1989) up to his first novel, Periférica Blvd. Ópera rock-ocó (2004). The analysis takes into consideration the use of narrative procedures identified as NeoBaroque and largely used during the so called Latin America's cosmopolitan period (1880-1940). Cárdenas experiments with the way in which oral representation is spoken in marginal sectors of Bolivian society, especially those from La Paz, and makes use of visual and sound procedures that have a Neo-Baroque dramatic quality. The complex result of the representation demands an active participation by the reader.
\end{abstract}

Keywords

Bolivian marginal sectors of society, Latin America's cosmopolitan period, Neo-Baroque narrative procedures, orality 


\section{Resumen}

Este artículo examina la primera etapa de la obra narrativa de Adolfo Cárdenas Franco, desde la colección de cuentos Fastos marginales (1989), hasta su primera novela, Periférica Blvd. Ópera rock-ocó (2004). En el análisis, se toma en cuenta el uso que hace el autor de procedimientos narrativos identificados como neobarrocos y practicados durante el periodo del cosmopolitismo hispanoamericano (1880-1940). Cárdenas experimenta con la representación oral del habla de los sectores marginales de la sociedad, especialmente de La Paz, y su narrativa se distingue por una teatralidad neobarroca constituida por procedimientos visuales y de representación sonora. El complejo resultado de esta representación demanda la activa participación del lector.

\section{Palabras claves}

Cosmopolitismo hispanoamericano, oralidad, procedimientos narrativos neobarrocos, sectores marginales de la sociedad boliviana

La obra de Adolfo Cárdenas Franco (Bolivia, 1950) escrita entre 1980-2004 constituye la primera etapa de su narrativa ${ }^{1}$ y requiere ser estudiada tomando en cuenta no solo la propia tradición literaria boliviana sino también la hispanoamericana, fundamentalmente porque gran parte de sus procedimientos narrativos -identificados como neobarrocos- fueron practicados durante el periodo del cosmopolitismo hispanoamericano (18801940): modernismo y vanguardismo.

Además, esta primera etapa se distingue por la representación oral del habla, el discurso neobarroco y la teatralidad neobarroca. Cárdenas logra captar o conservar ciertos giros lingüísticos de distintas hablas, pero al mismo tiempo los altera. No busca representar ficcionalmente, y de manera estática, un tipo único de identidad local, sino que experimenta literariamente con el

\footnotetext{
${ }^{1}$ La mayor parte de los primeros cuentos de Cárdenas aparecieron en la década de los ochenta y fueron reunidos en Fastos marginales (1989). Luego publicó los libros de cuentos Chojcho con audio de rock p'ssahdo (1992), El octavo sello (1997), y la novela Periférica Blvd. Ópera rock-ocó (2004). Posteriormente publicó Doce monedas para el barquero (2005), tres narraciones en Tres biografías para el olvido (2008) y El caso de Pérez de Holguín (2011), obras que requieren un estudio aparte.
} 
lenguaje oral y marginal de la sociedad boliviana, en particular la paceña. Parte de esta narrativa se distingue por una teatralidad neobarroca constituida por procedimientos visuales y de representación sonora; la complejidad del sentido de la representación y la referencia a otras artes y, por tanto, la activa participación del lector.

Algunas de las características de los cuentos de Cárdenas han sido descritas como particularidades de la heterogeneidad literaria y la imbricación cultural (Orihuela 1997, 418-419; Rodríguez Márquez 210-211) o como el espacio del choque de contrarios (Villena 432). Su primera novela, Periférica $B / v d$., ha sido comparada a una cámara de resonancias y como parte de una "larga tradición de hermetismos transgresores y fértiles que han trizado la lengua" (Prada 3). En diálogo con estas propuestas, ensayaré nuevas lecturas de los temas propuestos previamente.

\section{Cosmopolitismo y neobarroco}

Para estudiar la narrativa de Cárdenas es necesario considerar el periodo cosmopolita de la literatura boliviana y latinoamericana, comprendido por el modernismo y el vanguardismo. El cosmopolitismo empezó con el modernismo (Fernández Retamar 85) y el vanguardismo continuó experimentando hasta el extremo los proyectos modernistas. Ambas corrientes -estudiadas tradicionalmente por separado y contrapuestas entre sí- conforman el cosmopolitismo y actualmente "han sido reunidas bajo una nueva categoría: la modernidad” (Rivera Rodas 2010, 13).

La narrativa hispanoamericana contemporánea surgió bajo la influencia del periodo cosmopolita de nuestra literatura. En 1970, el venezolano Arturo Uslar Pietri (1906-2001) afirmó que la novela contemporánea nace a la sombra del modernismo (101). Se ha dicho también que "el proceso de renovación de la novela hispanoamericana no comienza sino con el inicio de la Modernidad, es decir, en el periodo modernista", donde se debe situar el origen del verdadero cambio de la narrativa hispanoamericana y sus efectos hasta el día de hoy (Gálvez Acero 34).

Dentro de la tradición literaria boliviana, la narrativa de Cárdenas tiene su antecedente en la poesía de Jaimes Freyre (1868-1933). El ensanchamiento de la materia lingüística y la enumeración de términos para describir un objeto o acontecimiento se evidencian en poemas como "Siempre" donde, por ejemplo, "[e]l sujeto del soneto, pese a los esfuerzos de los múltiples significantes del 
discurso, permanece indefinible" (Rivera Roda 1988, 280). Como veremos más adelante, procedimientos literarios semejantes son utilizados constantemente por Cárdenas en Periférica Blvd.

Los poetas vanguardistas hispanoamericanos incursionaron en la narrativa y ejercitaron diversos procedimientos como el monólogo interior, la diversificación del punto de vista narrativo, la experimentación lúdica con el lenguaje y la tipografía de las letras, etc. Hugo J. Verani señala el alto impacto que tuvo la vanguardia en la producción literaria que le prosiguió: "El asalto de las vanguardias contra toda normatividad opera progresivamente sobre la literatura hispanoamericana [...] prepara el terreno a la gran narrativa posterior y es necesario reconocer su función fertilizadora en la evolución de la literatura hispanoamericana" (69). ${ }^{2}$ El trabajo gráfico de Cárdenas, por ejemplo, se remonta a la obra de Hilda Mundy (1912-1982) Pirotecnia (1936), donde abunda el uso del grafismo y de los espacios en blanco. ${ }^{3}$ La importancia de estudiar y reconocer las características del periodo cosmopolita de la literatura boliviana permite comprender mejor el lugar que tiene la narrativa de Cárdenas dentro de la historiografía literaria nacional, no solo como un hito importante dentro de la narrativa boliviana, sino también como la continuación de proyectos literarios previos.

En el periodo cosmopolita y en la narrativa del siguiente periodo existe la presencia insistente de lo barroco. Mariano Picón Salas (1901-1965) señaló en 1944 que "[a] pesar de casi dos siglos de enciclopedismo y de crítica moderna, los hispanoamericanos no nos evadimos enteramente del laberinto barroco" (107). Posteriormente, José Lezama Lima (1910-1976) también reconoció que "El barroco aparece en distintos países, y en diversas épocas reaparece como una nueva tentación y un reto desconocido" (45). El catalán Eugeni D'Ors (1881-1954) explicó esta persistencia asegurando que el barroquismo es una

\footnotetext{
2 Nelson Osorio establece que la vanguardia hispanoamericana tiene una "enorme importancia renovadora y fertilizadora a la vez" en la literatura de la región, ya que en ella encontramos "en mayor o menor grado, casi todos los elementos que caracterizan la producción literaria de nuestros días". Por esta razón, continúa, es indispensable conocerla en toda su magnitud, como una plataforma para la "comprensión histórica del proceso literario que actualmente vivimos" (XXXVII).

${ }^{3}$ Mundy afirma: "No se puede negar la eficacia del graficismo [...] Todos los signos hacen el papel de grandes inductores gratuitos que inducen a los lectores hacia una segunda intención escondida por coordinación o subordinación de pensamiento..." (Villanueva 73).
} 
"constante humana" que retorna en las manifestaciones artísticas en distintas épocas y civilizaciones (citado por Carpentier 110, el énfasis es de Carpentier). Por eso, en 1975, Alejo Carpentier (1904-1980) consideró irrefutable la definición de D'Ors y afirmó que se debe "borrar de nuestras mentes" que el barroco sea una creación del siglo XVII (110). Para ilustrar esto en la literatura hispanoamericana Carpentier se preguntó “¿qué cosa es el modernismo, sobre todo en su primera etapa, sino una poesía sumamente barroca? Es toda la primera etapa de Darío. Y hay un barroco que llega ya al absurdo, que llega al garabato, que llega al exceso en la poesía de un Herrera y Reissing" (124). ${ }^{4}$ Carpentier traza así una relación entre lo barroco -como una constante en la creación artística- y el cosmopolitismo. Para Carpentier, lo barroco se encuentra en novelas como La vorágine (1924) o Canaima (1935) de Rómulo Gallegos (1884-1969); y también en la obra de Miguel Ángel Asturias (18991974). Por último, continúa Carpentier, lo barroco igualmente se encuentra en la novela contemporánea cuyos novelistas "traducen el ámbito americano, tanto ciudadano como de la selva o de los campos, de modo totalmente barroco" (124).

De este modo, lo barroco se manifiesta durante el periodo cosmopolita y permanece en la literatura hispanoamericana del siglo XX con sus propias particularidades. Severo Sarduy (1937-1993) utilizó por primera vez el término "neobarroco" al hablar de las características barrocas en la narrativa latinoamericana contemporánea en su ensayo de 1972 "El Barroco y el Neobarroco". ${ }^{5}$ Pero como he explicado, varias de estas características barrocas no son propias de la narrativa contemporánea, sino que aparecen durante el modernismo y el vanguardismo hispanoamericano. El mexicano Gonzalo Celorio dice que se puede reconocer "su condición barroca como una de las señas de identidad de la narrativa hispanoamericana contemporánea" (99), pero "estas características formales no constituyen por sí mismas una estética específica, pues ni son privativas del estilo barroco" (77).

4 Gálvez Acero afirma lo siguiente de la modernidad literaria hispanoamericana (modernismo y vanguardismo): "De ahí que la Modernidad, en definitiva, se defina como la estética del cambio, de lo asistemático, lo fragmentario, lo discontinuo" (21). Los términos que la crítica ha utilizado para explicar el cosmopolitismo son semejantes a los usados por la crítica que explica el neobarroco latinoamericano (Sarduy, Chiampi) como veremos adelante.

5 Como dijo Sarduy: "El barroco actual, el neobarroco, refleja estructuralmente la inarmonía, la ruptura de la homogeneidad, de logos en tanto absolutos, la carencia que constituye nuestro fundamento epistémico. Neobarroco del desequilibrio, reflejo estructural de un deseo que no puede alcanzar su objeto, deseo para el cual el logos no ha organizado más que una pantalla que esconde la carencia" (183, el énfasis es mío). 
Picón Salas explica que el Barroco español fue modernamente audaz en la forma pero de "extrema vejez en el contenido" (105). En Hispanoamérica, el Barroco tuvo "nuevas metamorfosis" debido al "medio primitivo", "el choque de razas", y "la acción violenta del trasplante" (106). Por eso, a pesar de que la cultura barroca entró primeramente a América como producto de la invasión colonial europea, el neobarroco -como un procedimiento creativo constante en distintas épocas-, no es una deficiencia en nuestra literatura, pues ha sido inevitable que los escritores hispanoamericanos como Cárdenas penetren en la realidad de sus regiones como en un laberinto barroco para indagar por la especificidad o diferencia americana.

\section{Representación del lenguaje oral}

En su obra, Cárdenas no solo representa el habla de sus personajes, sino que lo altera. Recupera y trastoca la oralidad: no formaliza ningún tipo de habla, no abdica de su ininteligibilidad, porque el neobarroco es una antípoda de la expresión oral. ${ }^{6}$ Esta representación oral permite primeramente dar a los personajes características intrínsecas (económicas, sociales, étnicas o de género, etc.) sin necesidad de recurrir a la descripción enunciativa. En sus textos no existen introducciones descriptivas de un narrador para presentar a un personaje. La oralidad representa primordialmente el habla de distintos grupos sociales de la ciudad La Paz y de otros departamentos de Bolivia. Incluye igualmente el habla de otras naciones hispanoamericanas y el habla de personajes que tienen como idioma nativo el inglés, pero que tratan de expresarse en castellano. Desde los cuentos de Fastos marginales, el autor no describe las características de los campesinos aymaras, como se ha hecho en la narrativa indigenista, solo representa ficcionalmente su expresión oral. En este sentido, incluso los "errores" ortográficos de los textos son una forma gráfica de representar a un personaje letrado o iletrado. De manera similar a las vanguardias hispanoamericanas, el narrador transgrede el orden literario establecido con un lenguaje oral y una naturalidad coloquial de inmediata vivencia en la lectura del texto. Y esto permite que el lector reciba una gran variedad lingüística.

\footnotetext{
${ }^{6}$ Rodríguez Márquez señala claramente: "Adolfo Cárdenas trabaja sobre la base de lenguajes orales ficticios que buscan evocar de alguna manera el lenguaje oral 'real' en el cual el idioma indígena altera marcadamente la fonética y la sintaxis castellanas" (211).
} 
En la narrativa de Cárdenas existe una inestabilidad del discurso o del enunciado, pues estos están en permanente transformación. En el cuento "Chacharcomani" de Fastos marginales encontramos un fragmento que ilustra esta inestabilidad. En las primeras líneas el narrador enuncia metáforas mediante una expresión formal del castellano. Pero inmediatamente aparece una transformación del enunciado. La oralidad sobrepuja la expresión formal del idioma. El narrador de este fragmento también es inestable pues, cuando la enunciación se distorsiona y "diluye", esta da lugar a otra voz narrativa dentro de la misma enunciación:

Rebota el sol en las piedras, destiñendo el aire a manotazos, pisoteando el polvo seco que se cocina en los resquicios de sombra y que no bastan entre todos para cobijar la inmensidad enclavada en algún lugar del torrente de brasas impalpables que sorben la memoria detenida en una tregua del tiempo en que la Satuca queraba lúnica quen el pueblo sabía donde yostaba, hasta mi cuarto de la loma siaviá largau la vieja, golpeando la puerta comu si alguien lastuviera persiguiendo, sin hacerse de caso de los mordiscos del Cual, gritando como pa que hasta en abajo lascuchen (Fastos 45).

Recursos similares se encuentran en relatos como "Retrato de grupo con Pompidou" del mismo libro de cuentos. Pero además de usar variadas formas de hablas, Cárdenas hace uso del coba de manera exhaustiva. Según Víctor Hugo Viscarra (1958-2006), el coba es el secreto "lenguaje marginal boliviano" (13). Por esta razón, existe cierto hermetismo y dificultad al leer algunos de sus textos. A Cárdenas le interesa el coba porque los usuarios de este lenguaje desechan y renuevan activamente los vocablos hasta alcanzar niveles extremos. Esto se puede ilustrar ampliamente en Periférica Blvd. (52). Pero el coba no permanece siempre secreto, sino que logra circular por distintos espacios de la sociedad, como lo explica Viscarra: desde los márgenes, los vocablos "caminan libremente por las calles, tanto en la boca del universitario como del oficinista, quienes lo utilizan sin preocuparse de que las definiciones usadas estén o no incluidas en algún diccionario" (14). Por lo tanto, el lector potencial de la obra de Cárdenas adquiere "cierto" conocimiento del coba sin necesidad de vivir el mundo del hampa.

Sin embargo, el uso del coba no es el único elemento que hace hermética la narrativa de Cárdenas. Igual función cumple el trabajo de distorsión que el escritor hace con este lenguaje que busca comunicar su sentido mediante el contexto del relato. El trabajo con el coba es intensamente estético y artificial. Reinventando artificiosamente el coba, el autor constituye términos propios cuyos significados son comprendidos dentro del texto literario, en el proceso 
de la lectura. Sus textos resultan tener características herméticas o codificadas no solamente porque mezclan las hablas, las jergas y el lenguaje marginal boliviano, sino porque recrean y reinventan la materia lingüística marginal. Este autor utiliza un coba casco, pues escribe trastocando el coba. ${ }^{7}$ Este escritor escoge el espacio de la marginalidad urbana como un espacio productivo para la creación. Usa y recicla el material lingüístico marginal por razones estéticas. ${ }^{8}$ Pese a que el uso de hablas y jergas intenta describir a los personajes, Cárdenas busca con esto un efecto de imprecisión e indefinición. La incomunicación que se puede producir entre el texto y el lector es semejante a la incomunicación entre los personajes de la novela, como explicaré a continuación.

La ininteligibilidad es un rasgo constante en las narraciones de Cárdenas. En el capítulo "Sueño de reyes" de Periférica Blvd., la expresión del cabo Juan -un personaje de ascendencia aymara que cuenta su experiencia musical autodidacta en la ciudad de La Paz y la conversación que tuvo con un músico inglés- representa la oralidad del habla del indígena castellanizado y refiere también al idioma inglés. La representación oral está en constante transformación. Los sintagmas que representan las hablas o idiomas se amontonan, "medio en engles, medio castellano, medio aymaras, medio quechuas", causando confusión y gozo ante el placer de la imprecisión:

[...] ona vez, ona gropos del esterior ha lligaro: Yetro creo y yo di contrauantos mintraro al hotel donde sián alojaro e los ckanckas asé mocionaros: ou que exoticou usted abourigen? mián hecho pasar e yops asé medio en engles, medio castellano, medio aymaras, medio quechuas hesplicaro pss o sea yo mósico tamien e ono [...] e me ha dijaro on manualcitos en inglis pero que yo lentendo porque en mi puelbo, había pss o sea pastores mitorestas (Periférica 135).

Algunas veces, la ininteligibilidad impide que el lector comprenda plenamente el texto. De igual modo, los personajes no pueden entenderse entre sí debido a las enigmáticas hablas que utilizan. Esto ya es explícito en "Retrato de grupo con Pompidou", mientras Rolando está en medio de una conversación: "-No chapo naranjas y mi traductora está perdida en medio de esta neblina que no se me disipa" (Fastos 122). En el cuento "Chojcho con audio de rock p'ssahdo", del volumen de cuentos con el mismo nombre, el teniente

\footnotetext{
7 Según Viscarra, un cobero casco es un "individuo que habla el Coba trastocando las palabras" (37).

8 Orihuela ha dicho que el contexto urbano marginal es "un nuevo espacio provocador, altamente significativo, que está determinado, principalmente, por una resuelta y muy creativa productividad" (Orihuela 2003, 221).
} 
Villalobos continuamente se burla de la ininteligibilidad de las conversaciones del cabo Fernández ya que regularmente no puede entenderle, y el teniente Oquendo reclama el hecho de que no puede comprender ni a Villalobos ni a Fernández: "qué declaras waca bolas; vos y tu jefe si que están hechos uno para el otro, no te entiendo..." (Chojcho 43). En Periférica Blvd. cada personaje y cada grupo social tiene en sí un sistema propio (enigmático) de comunicación y cuando se encuentran se produce un efecto de tensión y clausura del sentido (24, 205 y 259). Pero además, esta incomunicación se establece en relación jerárquica, pues Oquendo no comprende al teniente Villalobos, este a su vez no comprende a Fernández y Fernández se burla de la forma de hablar del cabo Juan. ${ }^{9}$ La ininteligibilidad del lenguaje sucede también entre los personajes considerados marginales. Cuando Maik conoce a la hermandad de la clefa declara: “...y esa es toda la onda- termina el ñato sin que casi nadies le haya entendido mucho pero yo sí..." (50). Y luego relata: "una zonita nomás...y la mayoría tratando de averiguar una zonita? Ques una zonita hasta que alguien aclara: un cacho de bayer y lo más chilas:ques bayer no?" (51).

Las distintas representaciones de hablas de la inusual escritura de Cárdenas nunca logran formalizarse porque no buscan la totalidad, el plutonismo o la plenitud barroca. Para Lezama Lima el Barroco americano -el colonial- tiene primeramente una tensión, luego un plutonismo "que rompe los fragmentos y los unifica" $y$, finalmente, un estilo plenario, no degenerescente... (46). Sarduy sostiene que este primer Barroco en América tiene un universo móvil y descentrado, pero aún armónico. En contraste, establece que el neobarroco es inarmónico, una ruptura o desarticulación con lo hegemónico, donde nada logra unificación: "el barroco actual, refleja estructuralmente la inarmonía, la ruptura de la homogeneidad" (183). Sarduy define al neobarroco como "reflejo necesariamente pulverizado de un saber que sabe que ya no está apaciblemente cerrado sobre sí mismo: arte del destronamiento y la discusión" (183). En base a lo dicho, puedo afirmar figurativamente que si el primer Barroco americano es plutónico (Lezama Lima), entonces, el actual barroco contemporáneo es magmático. El neobarroco es como un magma en continua fusión de la masa ígnea formada por residuos y escoria. El magma neobarroco no se consolida o solidifica, no termina en forma plena. Lo que predomina en la escritura neobarroca es el movimiento constante, lo que impide la petrificación de sus elementos: no

\footnotetext{
${ }^{9}$ El mismo personaje Severo Fernández -segregado por sus superiores por la manera en que habla el castellano- se burla del cabo Juan Rosas: "Y como el cabo le tira en castellama, mejor yo se lo traduzco lo que declara que habiá visto, pa que se'ntienda en el informe no?" (Periférica 82).
} 
alcanza la plenitud o armonía. Esta imagen del magma en continua fusión ilustra la escritura neobarroca de Cárdenas como en perpetua desarticulación de la escritura convencional. Es una escritura que destrona, pero que no se establece de forma plena o hegemónica. La incesante irregularidad de su estilo no pretende instaurarse, sino que continúa en permanente transformación.

Esa constante transformación del uso convencional de la lengua en la escritura de Cárdenas continúa una tradición literaria hispanoamericana. Con respecto a ciertos movimientos vanguardistas, Jorge Schwartz señaló que las vanguardias hispanoamericanas tuvieron proyectos utópicos para pensar un nuevo lenguaje o para renovar los lenguajes existentes. Por ejemplo, Borges y "el idioma de los argentinos"; Xul Solar y el "neocriollo" y el "pantalengua". Estos proyectos literarios apuntaron a una modificación y distanciamiento del castellano normativizado porque entendieron que mantener intacta la tradición lingüística europea "significa estancarse en el pasado colonial, no reconocer el carácter evolutivo de la lengua, negar en última instancia la propia tradición americana" (Schwartz 33). De aquí que, a pesar de algunos hermetismos, tanto la escritura de cierta vanguardia hispanoamericana como la escritura neobarroca, logran una identificación y descripción de lo americano. En 1975, Carpentier dijo en una entrevista: "Hay que buscar en América las cosas que no se han dicho, las palabras que no se han pronunciado. Y para este fin habría que encontrar un vocabulario que sea ante todo barroco" (citado en Chiampi 114).

Esta actitud iconoclasta con respecto a la representación del habla en la literatura hispanoamericana se debe a la diversidad de idiomas originarios y a la variedad dialectal del castellano en América, cuyo origen remite al periodo colonial. Esta distinción americana se encuentra representada en obras como El primer nueva corónica y buen gobierno (1615) de Felipe Guamán Poma de Ayala; y más aún, este fenómeno lingüístico fue reflexionado tempranamente por el Inca Garcilaso de la Vega en sus Comentarios reales de los Incas (1609). La preocupación por las hablas y la identidad americanas continuó durante el siglo XIX como estrategia de oposición a una herencia colonial estática. A principios del siglo $\mathrm{XX}$, los vanguardistas hispanoamericanos defendieron la idea de una lengua americana en contra del conservadurismo de las academias. Por todas estas razones, hay que situar primeramente en América, la tradición literaria de la obra de Cárdenas. 


\section{Algunos procedimientos neobarrocos}

Una parte de la obra de Cárdenas escrita entre 1980 y 2004 se caracteriza por la fragmentación, la ambigüedad, el exceso, el juego, etc. Ante estas formas irracionales de escritura es necesario recurrir a discursos críticos racionales para intentar explicar lo irracional. Al comentar la obra de Cárdenas no es suficiente señalar características como el exceso o el hermetismo, sino explicar en qué consiste esa abundancia, etc. Es importante reunir y elaborar un conjunto de términos básicos para proveer así cierto orden o guía en la lectura. Por eso, me referiré nuevamente a "Barroco y neobarroco" de Sarduy, quien mediante un discurso crítico formal describe y analiza obras literarias latinoamericanas que manifiestan características irracionales de escritura. ${ }^{10}$ Describiré algunos procedimientos neobarrocos que Sarduy propone a nivel del signo o unidades mínimas de significación divididas en el plano de la expresión y del contenido. También, consideraré las propuestas de la brasilera Irlemar Chiampi, quien propone otros términos para hablar de mecanismos neobarrocos a nivel de los enunciados y el relato, y no solamente a nivel del signo, como lo hace Sarduy. Ejemplificaré algunos de estos procedimientos con pasajes de la obra de Cárdenas.

\section{Aspectos neobarrocos a nivel del signo}

En el plano de la expresión, Sarduy propone tres constantes en la escritura neobarroca: la sustitución, la proliferación y la condensación (172-173). En Periférica Blvd. abundan ejemplos de proliferación de palabras. Luego de una inesperada fuerza sonora procedente de un altoparlante situado detrás de Severo Fernández, se lee el malestar que le causó: "miá dejado patidifuso, turulato, patalético, soponciado" (260). En este caso, es posible distinguir el significado de tres de estas palabras (patidifuso: quedarse parado con asombro; turulato: quedarse estupefacto; soponciado: perder el conocimiento). Sin embargo, desconocemos el significado de "patalético" (que podría ser un neologismo derivado de "pataleta": rabieta infantil). La proliferación aparece ante el intento o la dificultad de nombrar algo. Considerando la explicación de Sarduy, el personaje de Cárdenas describe

\footnotetext{
${ }^{10}$ Años después, Omar Calabrese observó que a pesar de la decadencia de ciertas formas de racionalidad en el arte, no es posible eliminarla. Al contrario, hay que buscar formas de racionalidades diferentes y adecuadas para explicar lo contemporáneo (13).
} 
su experiencia con una cadena de términos que además de circunscribir a algún signo lingüístico ausente, logran obliterar -obstruir- el sentido.

Otro neobarroquismo en el plano de la expresión es la condensación de signos. Para Sarduy, en la condensación se procede un intercambio entre los significados de dos significantes, de donde surge un tercer término que resume a los dos primeros y contiene a veces un pequeño elemento paródico. Por ejemplo, en Periférica Blvd. aparece "pepsicología" (108), condensación de la bebida gaseosa "Pepsi" y la ciencia de la psicología. O "agusanados" (63), que proviene de la condensación de aguzado y gusano. Existe además otra variación de la condensación, que denomino frases condensadas como "Silpancho Villa" (178), frase condensada de "silpancho" (comida tradicional cochabambina) y el nombre de uno de los líderes de la Revolución mexicana, Francisco Villa (México, 1978-1923).

Para Sarduy, en el plano del contenido, la intertextualidad y la intratextualidad tienen funciones imprescindibles. La intertextualidad se manifiesta mediante la cita y la reminiscencia. La cita es para Sarduy la incorporación de un texto extranjero a uno nuevo sin que su voz se altere ni sus elementos se modifiquen. En la obra de Cárdenas el epígrafe es una manifestación constante de la citas. Cada capítulo de Periférica Blvd. comienza con un epígrafe. El recurso a la cita aparece también en sus cuentos iniciales, pero con epígrafes de letras musicales como el de "Retrato de grupo con Pompidou" (Fastos 114) y otros relatos de El octavo sello (1997). En Periférica $B / v d$. hay varias citas musicales de música popular latinoamericana como los boleros "sombras nada más...", "bésame, bésame mucho" (27 y 247) y otras. La reminiscencia es otro tipo de intertextualidad que, según Sarduy, surge cuando el texto extranjero se funde al primero de manera indistinguible, con el requisito de no implantar sus marcas, pero constituyendo los estratos más profundos del texto receptor. Para Sarduy, la cita neobarroca puede entenderse como un texto secreto que no tiene que ser necesariamente descifrado por el lector. De aquí que no implanta explícitamente sus marcas textuales, sino que tan solo matiza el texto receptor en el cual se inserta. En Periférica Blvd. existen numerosas reminiscencias musicales que reproducen este comportamiento. Durante un matrimonio, Severo conoce a un personaje que afirma "Soy el Mario Rojas Yujra" (210, el énfasis es mío). Esta reminiscencia musical refiere al grupo de cumbia boliviano "Maroyu". Vano sería tratar de identificar todas las reminiscencias que presenta este texto, basta señalar que su objetivo es siempre activar un recuerdo en la memoria del 
lector, un recuerdo vago e impreciso. Además, probablemente en muchos casos se trata de reminiscencias íntimas que Cárdenas disfruta en secreto.

En el plano del contenido hay que distinguir también el intratexto en cuanto "unidades mínimas de parodia, como un elemento decorativo" (Sarduy 176). Sarduy propone codificar la lectura de estas unidades textuales en filigrana y las llama gramas. La intratextualidad nos dice este teórico, supone tres clases de gramas: fonéticos (anagrama, caligrama, aliteración, palíndromo), sémicos (anagrama e idióm) y sintagmáticos. Ilustraré a continuación dos gramas fonéticos relevantes en la narrativa de Cárdenas: la aliteración y el palíndromo. La aliteración es la repetición de uno o varios sonidos en una palabra o enunciado: "Hambre de fiambre" (Periférica 119) o "grave, graaaajve al jarabe no?" (260), por ejemplo. Sarduy dice que detrás de estas frases aliteradas no hay ninguna otra lectura que se esconda, y que la aliteración se dirige a sí misma: "lo que su máscara enmascara es precisamente el hecho de no ser más que una máscara, un artificio y un divertimento fonético, que son su propio fin" (179). Este propio fin intratextual se observa en la frase "hambre de fiambre", que se parodia a sí misma al establecer una ironía entre el castigo del hambre y el no tener fiambre para comer. Esta operación describe también el exceso verbal de la escritura neobarroca mediante la repetición.

El palíndromo es otro de los gramas fónicos más utilizados en Periférica Blvd. Básicamente, palíndromo significa 'desandar lo andado', como Tamar, que significa Marta, el nombre de un personaje. Este procedimiento es frecuente en el argot y en el código cifrado. En Periférica Blvd. abunda esta variedad de palíndromo, especialmente con relación a términos coba como "sapa" (pasa), "tromae" (maestro), "gotra" (trago) (153 y 154) y varios otros $(155,173,267)$. El fin de estos palíndromos son ellos mismos, se refieren a sí mismos, como en la aliteración. Sin embargo, los palíndromos se distinguen de la aliteración por la inversión y descomposición de las sílabas. Además, esta transformación de los significantes constituye un tipo de espectáculo en el texto, tema que explicaré posteriormente.

\section{Aspectos neobarrocos sintácticos}

Por su parte, Irlemar Chiampi intenta proponer una semiología de la narrativa neobarroca a partir de una frase, grupos de frases o enunciados. Esta operación analítica abandona el estricto aspecto verbal (el signo) -como hemos visto en el análisis de Sarduy- para pasar al aspecto sintáctico (el de las 
relaciones entre enunciados) (Chiampi 120-121). La estudiosa habla de lo indecible cuando la descripción del narrador muestra perplejidad "ante lo innombrable, mediante verbos y adjetivos que recortan la categoría de lo insólito" (103). En "La madame" de Chojcho con audio de rock p'ssahdo, luego que la Madame "conquista" a Elvis Pelvis: "Las especulaciones surgieron como una metralla acribillando las espaldas de Elvis" de manera insólita. La gente llamó a Elvis: embrujado, engualichau, karimunacha; y al acontecimiento: “Obra de Satanás, hechicería, magia negra, herejía, anatema, magia roja, trastorno mental, locura temporal, amnesia fijativa, mesmerismo y todo cuanto pudo inventarse al respecto" (Chojcho 25). En Periférica Blvd. varios policías entran a un laberíntico local y se encuentran rodeados de un grupo de extraños comensales. Ante el desconcierto, los policías intentan describir lo encontrado con más de una decena de frases (79). Chiampi explica que este intento de explicar algo refleja el malestar del narrador ante lo innombrable (105). En ambos ejemplos, las descripciones son colectivas y lo indecible produce el exceso verbal. Los personajes, perplejos ante lo insólito, no limitan sus descripciones. Al mismo tiempo, no explican o determinan nada, al contrario, incrementan el desconcierto.

Para Chiampi, otra característica neobarroca a nivel del relato es "la amplificación de los enunciados, no como un mero ejercicio dilatorio y dilatatorio del relato, sino como una aplicación semántica y narracional” (121). La amplificación por descripción es la amplificación de un breve enunciado o un "núcleo funcional o una matriz". Es un procedimiento "sencillo y frecuente" pero "exagerando". Busca el abultamiento discursivo y el avance del contenido de la narración (126-127). En el cuento "Retrato de grupo con Pompidou" de Fastos marginales, el personaje principal, Rolando, es objeto de burla por su sobrepeso. El nombre "Rolando" y su condición de "gordo" son matrices o núcleos funcionales amplificados desde el inicio hasta el final del cuento:

[Rolando inicia la narración]: ...o cubito o berlín, lo graciosos: odre o blader los envidiosos y gordo o pompo mis amigos... Pompito hermano... gordazo...... No lo han visto al bolacha? Al bolo alimenticio, al bólido, al bolivar... Hooooola gorrino, que tal glóbulo, ha llegado el gordo de américa... Mirá haber como le saltan sus Ilantas al gocho Ya pss che gordo abusivo (Fastos 115).

Rolando, interesado en una muchacha que tiene un novio activo en la política universitaria, decide ser más subversivo para conquistarla. Luego de participar en una huelga de hambre, los camaradas lo ovacionan con ironía: "iBravo gordachev, goldo meyer hemos triunfado...!" (120). Posteriormente, 
decepcionado del amor y la política, asiste a una reunión de letrados, quienes preguntan su nombre para conocerlo: "cual es tu barajo flash gordon... cual es tu chapa Rolo-bolo... Bollito mentiroso" (121-122). Además, otra variedad de la amplificación en este cuento es lo que llamo amplificación por nominación/adjetivación. En "Retrato de grupo con Pompidou" ya no hay solamente una amplificación de un núcleo funcional, sino el derroche de adjetivos dirigidos a Rolando: "Ya gordo flojo, tanque Díaz... apurate che, petaquita!" y por último "chef Guevara”, etc. (115 y 120). La amplificación por nominación/adjetivación aparece también en Periférica Blvd. cuando Villalobos se dirige a Severo amplificando la matriz de la palabra indio. Además, Villalobos insulta a Severo con otros nombres y adjetivos como indo-necio, aborigen, mula (el más usado), raza de bronce, indio Fernández, indio sicuri o larama $(266,28,20,247,249,251$ y 96). Este tipo de amplificación surge como una representación del acoso y discriminación en la sociedad, y no únicamente como un procedimiento creativo espontáneo.

La amplificación por relato es para Chiampi un tipo de amplificación que ya busca solamente la expansión de un núcleo, sino la "plena distorsión de la vectorialidad del relato" (129) mediante otros relatos: el relato-dentro-delrelato, donde se abandona el modo descriptivo por el modo de la narración. En "Alajjpacha" de Fastos marginales, el texto es narrado por Pelagio y su madre Ildefonsa, aymaras campesinos que trabajan para los patrones de una hacienda. La madre se dirige a su hijo muerto y le pide que recuerde el espantoso ataque de los indios a la propiedad patronal. Cuando Ildefonsa narra se insertan las narraciones breves de otros personajes de la hacienda y así nos enteramos de lo ocurrido. Además, la narración de lldefonsa es interrumpida constantemente por la narración del ánima de Pelagio que le habla a su propio cuerpo corrompido. La vectorialidad del relato, de esta manera, queda profundamente distorsionada. La diversidad de narradores y el anacrónico orden del relato de este texto aparecen también en otros cuentos del mismo volumen. Este procedimiento se verifica también en Periférica Blvd., donde el relato-núcleo del texto (la persecución de Maik por dos policías) se ve afectado por varios relatos que se insertan; varias voces heterogéneas trastocan la vectorialidad de la narración. En este texto, los narradores o voces que intervienen se entrecruzan con el relato-núcleo. El texto tiene un total de dieciséis divisiones, narradas por siete personajes y un narrador. Estos relatos, dentro del relato-núcleo, narran la vida íntima de los personajes, pasajes de sus vidas o descripciones de algún suceso, y no precisamente la persecución policial. Además, varios de estos capítulos están narrados por múltiples personajes que se suceden a la vez. 


\section{Teatralidad neobarroca}

Llamo teatralidad neobarroca al espectáculo de la escritura y de los personajes ante la participación activa del lector. Considero el término "teatro" según su significación primaria: "hacer" o "actuar"; y según la acepción de acción fingida o actuada frente a un público. Algunas modalidades de la teatralidad neobarroca en Cárdenas son las transformaciones de un significante, el despliegue de historietas gráficas, ornamentaciones visuales, representaciones sonoras y representación de artes como la música, el baile, la ópera, etc. Estas modalidades del texto sobre la página, como una "tela de fondo", ${ }^{11}$ están presentadas a manera de espectáculo ante un lector espectador.

Características similares se dieron en el arte del Barroco, pero como expliqué a un inicio, el barroquismo es una constante humana (Eugeni D'Ors) y no una creación europea del siglo XVII (Carpentier). Durante el Barroco, según Orozco Díaz, el teatro se impuso como un nuevo género intermedio entre lo escrito y lo improvisado, con el objeto de divertir y emocionar a las personas. En el Barroco el mundo se convierte en teatro, la vida toda es espectáculo, debido al efecto desbordante que tuvo el Barroco en la vida de la gente y en las demás artes (Orozco Díaz 1969, 237). La teatralidad neobarroca en la obra literaria de Cárdenas reside en el sentido de lo teatral como espectáculo en el proceso mismo de la impresión de la escritura, en la representación de los personajes y en el contenido temático de la narración.

La narrativa de Cárdenas hace hincapié en el carácter gráfico de los signos lingüísticos para activar el efecto visual y la representación sonora. En "Alajjpacha" se lee: "Y ai una noche antes eran los perros, esa noche los pututus. UUUUHHH UUUUUUHHHHHH ... comu ánimas viniendo por oleadas a agarrarse de 'ste pueblo con sus manos frías parecía" (Fastos 20). Varios cuentos ejemplifican una imbricación de la representación de sonidos. Esta representación se encuentra como tema en el relato y está expresada con gramas que afectan la tipología de las letras.

\footnotetext{
${ }^{11}$ Remito a Luis H. Antezana, cuando anota que: “En rigor, la página (y sus espacios) juega como un inter-texto (un texto-dentro-del-texto) que condiciona, a su manera, las significaciones del poema. Como una tela de fondo que, simultáneamente, recibe y ambienta las figuras que sobre ella se inscriben. En la poesía, el grafismo y los espacios conforman un sistema relativo de significaciones. No hay sentido para los espacios sin el grafismo, ni sentido para éste sin los espacios: se suponen mutuamente. En esta dimensión, el poema no "expresa" un contenido previo a su forma, el contenido es la forma que adquiere escrituralmente" (95-96).
} 
En Periférica Blvd. existen gramas transformistas, palabras que están afectadas a nivel del significante, la forma gráfica del signo, pero sin alterar sustancialmente sus fonemas. Estos gramas producen efectos visuales y efectos en la representación sonora que influyen en el sentido de la narración. En la novela, la policía ejerce su autoridad sobre otros personajes mediante la fuerza física. Para representar la violencia policial se usa en cuatro ocasiones la metáfora fonética "tchun": a) al inicio de la novela, el teniente Oquendo "tchun a uno de ellos, le mete un corto en su barriga" (Periférica 25); b) en el siguiente capítulo, en el local Sombras nada + , el teniente Villalobos "TCHUN un planchazo de sorpresa" al barman (44); c) luego de una emboscada en las catacumbas, el teniente grita “iQué mas sarna, qué maaas!” y

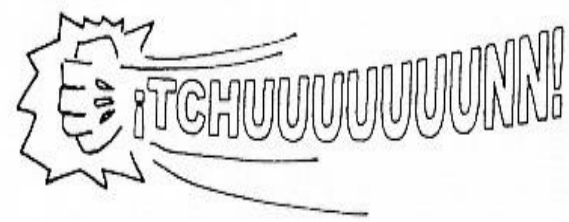

al personaje llamado Rin tin thinner; d) y finalizando el libro, Villalobos nuevamente "iTCHUNNNN!" (262) al pequeño Alex. Estos gramas exigen ser vocalizados para hacer vivir la escritura, para que mediante la interacción dinámica entre la voz viva del lector y la escritura inerte del autor se produzca el sentido completo del texto.

De manera similar, el grama "cuate", del nahuatl cóatl (serpiente o mellizo), se transforma figurativamente a lo largo de la novela como en un espectáculo. El grama "cuate" va sufriendo ciertas transformaciones peculiares: de "cuate" cambia a "cuats", "cuaternario", "cuat", “Q.A.T.”, "Q-aT", “Q-a-T cita” y "q-ates" (Periférica 15, 24, 27, 36, 54, 266 y 216). En estos casos, el significado del signo es el mismo, aunque el significante se transforma y mantiene la representación sonora. Estos gramas se prolongan más allá de su significado inmediato dentro de los sintagmas, tienen la función de cambiarse de "atavíos" ante los lectores/espectadores y activar la participación de estos. Recurre a puntos, guiones, etc., y no se limita al tamaño de las letras. Figurativamente, estos recursos son los afeites de los gramas y su fin es el espectáculo: presentarse y transformarse ante el lector. 
La narrativa de Cárdenas está concebida vigorosamente para ser vista y esto supone un espectador que contemple la ornamentación narrativa. Durante el Barroco, por ejemplo, los poemas también "suponen efectos de teatralidad; pero de una gran escena en la que las gentes todas toman parte" (Orozco Díaz 1988, 313). Entonces, si Cárdenas concibe su narrativa para ser visualizada, el lector tiene una mayor participación activa frente al "escenario" textual.

Cárdenas inventa varias formas de ornamentación narrativa. En "Balada para la bola" existe un caligrama en forma de epitafio dedicado a un personaje durante su funeral (Fastos 109). El caligrama ha sido empleado en diferentes épocas pero con distinta intensidad. En el Barroco, los caligramas fueron utilizados para la visualización de un poema. Y a fines del siglo XIX, el poeta mexicano José Juan Tablada (1871-1945) esgrimió este recurso para su poesía.

El cuento "Chojcho con audio de rock p'ssahdo" comienza con una historieta gráfica o cómic. Esta viñeta representa grafitis sobre un muro, el cual es leído y observado por Severo. En ese momento, el personaje y el lector potencial leen y observan la pared; a nivel de la recepción, ambos comparten al mismo tiempo un espacio semejante, obviamente el personaje dentro de la ficción y el lector fuera del texto. El cuento exige primeramente ser observado: leer es también contemplar. Los grafitis resaltan la importancia de la contemplación gráfica de la escritura junto a la lectura simultánea de la narración. De manera muy similar, en el Barroco los poemas eran utilizados sobre los túmulos en las exequias de personajes importantes y en las construcciones arquitectónicas. Lo escrito se estaba "dirigiendo directamente, como llamándolo, al visitante, al peregrino, al caminante, o simplemente a un espectador, para que se detenga, lea, contemple y considere lo que tiene ante sí..." (Orozco Díaz 1988, 300).12 Cárdenas convoca también al lector/espectador que recorre las páginas y lo invita a contemplar lo que está ante sus ojos.

Adicionalmente, Cárdenas añade otros gráficos, como aquellos que representan carteles de anuncios masivos (Periférica 207, 258 y 268). En el contexto del relato, estos grafitis y amplios anuncios están destinados a una colectividad urbana que refiere también a prácticas barrocas. Según Orozco

\footnotetext{
${ }^{12}$ En los certámenes de lírica se acudía en aquella época a la visualización de los poemas para que estos cobrasen sentido. La poesía contemplada "había de entrar como voces por los ojos" (Orozco Díaz 1988, 310). Los poemas incluso fueron pensados para dar una visión colectiva simultánea, acompañados de una voz que leía a la multitud, generando un sentido y expresividad teatral (316).
} 
Díaz, el Barroco abrazó la expresión de una cultura de masas ligada a la vida de las ciudades y construyó la sensibilidad y capacidad de reacción artísticosensorial de las masas. Con respecto a la poesía expuesta al público durante el Barroco, este crítico Díaz afirma: “... son esas formas literarias las que tienen su realización, no en la lectura aislada individual, sino en la audición y actuación colectiva directa cara al público..." (Orozco Díaz 1988, 296).

Además de añadir elementos visuales y de representación sonora, el título Ópera rock-ocó indica que la novela incluye la representación de otras artes. El rococó fue una de las últimas manifestaciones del Barroco que se expresó a través de varias manifestaciones artísticas, principalmente mediante la ópera, espectáculo de preferencia visual, sonora y popular. La ópera es un drama cantado, tiene un acompañamiento instrumental e incluye obviamente a un público espectador. Orozco Díaz dice que hoy, en el arte, como en otras épocas, se "ha producido un desbordamiento e interrelación de las artes, presidido igualmente por el imperio de lo visual y pictórico" (311). El incremento de estos aspectos en el Barroco tuvo como fin "la general teatralización de las artes" (315). ${ }^{13}$ En la novela, esta teatralización de las artes se hace evidente desde su inicio con un aviso al público lector con respecto a esta Ópera rock-ocó. Este anuncio contiene un reparto, un elenco de actores, cantantes, talleres de teatro y danza, un coro estable, invitados especiales, un ensamble tropical y una orquesta sinfónica de rock (9). Es una declaración previa del papel de los personajes y la teatralización de las artes. Con esta declaración previa, Cárdenas presenta a sus personajes como cantantes de ópera, músicos y bailarines. Este anuncio indica al público lector que los actantes de la novela son, además de personajes, artistas. Advierte que el contenido de la novela no es una simple representación mimética de la realidad sino una simulación compleja de teatralización. Esto produce cierto sentido de teatralización de la misma ficción, como si los personajes realizaran una doble representación. Incluso el tiempo del relato de la novela dura de doce de la media noche hasta las cinco de la madrugada, tiempo suficiente para la presentación de una ópera. Considerando las palabras de Orozco Díaz sobre el Barroco, Cárdenas tiene como narrador una alta conciencia de lo teatral

13 En El teatro y la teatralidad del Barroco Orozco Díaz señala que en esta modalidad artística existe una "general teatralización de la vida y del arte: el triunfo de la escena que lleva consigo la conciencia de lo teatral" (241). La vida "se invade de un sentido teatral, también, en consecuencia, se teatralizan todas las artes [...] Hasta el teatro aunque parezca redundancia- diríamos que se teatraliza" (240). 
porque impregna de un sentido teatral a toda la novela, por eso existe en el relato una teatralización de las artes.

En conclusión, los antecedentes de la primera etapa de la obra narrativa de Cárdenas (1980-2004) se encuentran en la tradición literaria del cosmopolitismo hispanoamericano y boliviano (modernismo y vanguardismo). Las características más importantes de su obra se encuentran con relación a esta genealogía literaria. Los cuentos de Fastos marginales contienen claramente particularidades neobarrocas que serán desarrolladas ampliamente en Chojcho con audio de rock p'ssahdo y Periférica Blvd., obras que son el resultado de un proceso creativo continuo y no como un hecho espontáneo. Cárdenas representa ficcionalmente las hablas y las recrea paralelamente hasta llegar al hermetismo. Lo ininteligible de esta narrativa es también una manifestación de la incomunicación entre los personajes; rasgo latente en la sociedad boliviana.

He descrito los mecanismos neobarrocos a nivel de los signos y los sintagmas considerando la reflexión teórica latinoamericana del neobarroco y entendiendo que, ante textos literarios caóticos, ambiguos y fragmentados, es necesario poder describirlos y explicarlos de manera formal y rigurosa. Si bien las características neobarrocas que he anotado no hacen de la obra de Cárdenas una obra exclusivamente neobarroca, es evidente que su narrativa posee una teatralidad neobarroca compuesta por el espectáculo de la escritura y los personajes, y la teatralización de distintas artes. Esto incluye la transformación de los signos lingüísticos y la ornamentación narrativa para producir efectos visuales y de representación sonora. Todo esto ante la mirada y lectura del lector.

\section{Bibliografía citada}

ANTEZANA, Luis H. 1986. Ensayos y lecturas. La Paz: Altiplano.

CALABRESE, Omar. 1999. La era neobarroca. Madrid: Cátedra.

CÁRDENAS FRANCO, Adolfo. 2004. Periférica Blvd. Ópera rock-ocó. La Paz: Gente Común.

---. 1997. El octavo sello. La Paz: Punto Cero.

---. 1992. Chojcho con audio de rock p'ssahdo. La Paz: D'la Piut.

---. 1989. Fastos marginales. La Paz: Vidrio Molido.

CARPENTIER, Alejo. 1984. Ensayos. La Habana: Editorial Letras Cubanas. 
CELORIO, Gonzalo. 2001. Ensayo de contraconquista. México: Tusketes.

CHIAMPI, Irlemar. 2000. Barroco y modernidad. México: Fondo de Cultura Económica.

FERNÁNDEZ MORENO, César, coord. 1986 [1972]. América Latina en su literatura. México: Siglo Veintiuno.

FERNÁNDEZ RETAMAR, Roberto. 1995. Para una teoría de la literatura hispanoamericana. Santafé de Bogotá: Caro y Cuervo.

GÁLVEZ ACERO, Marina. 1987. La novela hispanoamericana contemporánea. Madrid: Taurus.

KALIMÁN, Ricardo J., ed. 1997. Memorias de Jalla Tucumán 1995. Tucumán: Universidad Nacional de Tucumán.

LEZAMA LIMA, José. 1969. La expresión americana. Madrid: El Libro de Bolsillo.

ORIHUELA, Juan Carlos. 2003. "La peregrinación vigilante: tendencias de la narrativa boliviana de la segunda mitad del siglo XX". Hacia una historia crítica de la literatura en Bolivia. Tomo I. Blanca Wiethüchter y Alba Paz Soldán, eds. La Paz: PIEB. 200-225.

---. 1997. "La ciudad periférica (y la narrativa de Adolfo Cárdenas Franco)". Memorias de Jalla Tucumán 1995. Ricardo Kalimán J., ed. Tucumán: Universidad Nacional de Tucumán. 414-422.

OROZCO DÍAZ, Emilio. 1988. Introducción al Barroco. Tomo I. Andalucía: Universidad de Granada.

---. 1969. El teatro y la teatralidad del Barroco. Barcelona: Planeta.

OSORIO, Nelson, ed. 1988. Manifiestos, proclamas y polémicas de la vanguardia literaria hispanoamericana. Caracas: Biblioteca Ayacucho.

PICÓN SALAS, Mariano. 1944. De la conquista a la independencia. México, DF: Fondo de Cultura Económica.

PIZARRO, Ana, coord. 1995. América Latina: Palavra, Literatura e Cultura. São Paulo: Fundacão Memorial da América Latina.

PRADA, Ana Rebeca. 2004. "Una ópera rock-ocó". La Prensa. Suplemento Fondo Negro (La Paz) 12 de septiembre. 3. Reproducido en T'inkazos: Revista Boliviana de Ciencias Sociales 17 (diciembre): 147-157.

RIVERA RODAS, Óscar. 2010. "Historicidad y cosmopolitismo en la literatura hispanoamericana”. Cuadernos Americanos XXIV.1 (enero-marzo): 1146. 
---. $\quad$ 1997. “Discurso estético y modernidad en Gutiérrez Nájera”. Literatura Mexicana 8 (2): 625-653.

[http://www.revistas.unam.mx/index.php/rlm/article/view/36263] página descargada el 15 de mayo 2015.

---. $\quad$ 1988. La poesía hispanoamericana del siglo XIX: del romanticismo al modernismo. Madrid: Alhambra.

RODRÍGUEZ MÁRQUEZ, Rosario. 2008. “De mestizajes, indigenismos, neoindigenismos y otros: la tercera orilla (sobre la literatura escrita en castellano en Bolivia)". Tesis doctoral. University of Pittsburgh.

SARDUY, Severo. 1982. "El Barroco y el neobarroco". América Latina en su literatura. César Fernández Moreno, coord. México: Siglo Veintiuno. 167-184.

SCHWARTZ, Jorge. 1995. "Lenguajes utópicos. 'Nwestra ortografia bangwardista': tradición y ruptura en los proyectos lingüísticos de los años veinte". América Latina: Palavra, Literatura e Cultura. Ana Pizarro, coord. São Paulo: Fundacão Memorial da América Latina. 33-54.

USLAR PIETRI, Arturo. 1974. Breve historia de la novela hispanoamericana. Madrid: Mediterráneo.

VERANI, Hugo J. y Hugo Achúgar, ed. 1996. Narrativa vanguardista hispanoamericana. México: UNAM.

VILLANUEVA, Laura [Hilda Mundy]. 2004 [1936]. Pirotecnia. La Paz: La Mariposa Mundial/Plural.

VILLENA, Marcelo. 1997. "La voz y el espectro de la heterogeneidad (en los cuentos de Adolfo Cárdenas). Memorias de Jalla Tucumán 1995. Ricardo Kalimán J., ed. Tucumán: Universidad Nacional de Tucumán. 423-435.

VISCARRA, Víctor Hugo. 2004 [1981]. Coba, lenguaje secreto del hampa boliviana. La Paz: Correveidile.

WIETHÜCHTER, Blanca y Alba María Paz Soldán, eds. 2003. Hacia una historia crítica de la literatura en Bolivia. Tomo I. La Paz: PIEB.

\section{$(\mathrm{cc}) \mathrm{Br}$}

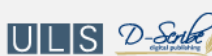

New articles in this journal are licensed under a Creative Commons Attribution 4.0 United States License.

This journal is published by the University Library System of the University of Pittsburgh as part of its D-Scribe Digital Publishing Program, and is cosponsored by the University of Pittsburgh Press. 